\title{
EXTENSION OF THE LIFE OF GTK 10-4 WORKING BLADES FROM EI 893 ALLOY AFTER LONG OPERATING PERIOD
}

\author{
A.F. BELYAVIN ${ }^{1}$, V.V. KURENKOVA ${ }^{1}$, D.A. FEDOTOV ${ }^{1}$, S.G. SALY ${ }^{2}$ and A.P. SHCHERBININ ${ }^{2}$ \\ ${ }^{1}$ «Paton Turbine Technologies» Ltd. \\ 26 Raketnaya Str., 03028, Kiev, Ukraine. E-mail: VKurenkova@patontt.com \\ ${ }^{2}$ Repair Enterprise «Ukrgazenergoservis», Subdivision of PJSC «Ukrtransgaz» of NJSC «Naftogaz Ukrainy» \\ 49 Mayakovsky Str., 08151, Boyarka, Ukraine
}

\begin{abstract}
During prolonged operation (thousands of hours) degradation of base material — EI 893 alloy — proceeds in working blades of GTK 10-4 unit under the impact of static and dynamic loads, temperature gradient, fuel combustion products, etc. Structural changes in the basic blade alloy influence the changes of its mechanical properties, compared to metal in initial state, namely, increase of ultimate strength, yield limit, hardness values and lowering of ductility characteristics take place and, therefore, also lowering of their creep resistance and high-cycle fatigue. For this reason, extension of service life of expensive items in turbine hot section is an extremely important task, which is solved by integrated restoration of initial structure and mechanical properties of EI 893 alloy. The objective of this work was studying GTE material state after operational aging on seven working blades (from sets with different operating lives), determination of their repairability and selection of modes of recovery heat treatment. It was found that during long operation periods at the temperature of $630-670^{\circ} \mathrm{C}$ an essential change of structural-phase state of base material proceeds in the working blades, which is manifested in dissolution, coagulation and non-uniform distribution of strengthening phase in matrix solution volume and carbide precipitation on subgrain boundaries within the grains and on grain boundaries, and formation of carbides of a more complex composition. It was established that optimum base structure with sufficient hardness and microhardness forms at two-step recovery heat treatment, namely, a certain reduction of difference in grain dimensions (mainly, 2-4 grain size point), reduction of density and dimensions of stable carbide phases in intergranular interlayers, and uniform and regular distribution of disperse strengthening phase. Structure recovery after recovery heat treatment leads to improvement of ductile characteristics $(\delta=33.2-35.6 \%)$ and, consequently, also of fatigue resistance at admissible values of strength and fracture toughness, that, on the whole, ensures the serviceability of reconditioned items. 16 Ref., 5 Tables, 10 Figures.
\end{abstract}

Keywords: high-pressure turbine (HPT), low-pressure turbine (LPT), recovery heat treatment (RHT), hardness, microhardness, ultimate strength, yield limit, ductility, fracture energy, deposited weld, heat-affected zone

Working blades of gas-pumping units (GPU) drive turbines are operating in combustion products of fossil fuel under complex temperature conditions, where the concurrent factors are high working temperature of gas flow; significant temperature gradients between the airfoil root and middle part; cyclic thermal stresses (starting, stopping, etc.); simultaneous impact of static tensile (centrifugal) forces; bending loads arising from the impact of pulsed gas flow and dynamic vibratory stresses.

When addressing the problems of reliability and extension of working blade operating life, the main element is control of structural changes proceeding in blade material, which lead to lowering of resistance to creep and high-cycle fatigue of metal, as about $80 \%$ of unforeseen fractures of parts in turbine hot section in service are of exactly fatigue nature. Magnitude of alternating loads can be up to 50-80 MPa, and total (equivalent) stresses, applied to blades in turbine I stage, reach $150 \mathrm{MPa}$ [1].
At present a significant number of GTK 10-4 GPU are operating in Ukraine in the main gas pipelines. Most of the units have exhausted their service life specified by manufacturer-plant, and, in keeping with industrial safety requirements in gas line compressor stations [1, 2], the need arises to provide engineering and economic substantiation of the approach to extension of the life of the main parts for a maximum term. This, primarily, pertains to extension of the period of safe and reliable operation of working blades of HPT, made from EI 893 alloy, which consists in providing the full cycle of RHT alongside performance of the required stages of welding/brazing repair. Solving the problem of maximum extension of GTK 10-4 GPU life is associated, in particular, with taking out of service and conducting destructive testing of material of the most representative main parts of GPU with maximum operating life, in order to determine the influence of operational factors on mechanical properties.

Wrought high-temperature alloy EI 893 VD has become extensively applied in manufacture of work- 
ing blades of gas-turbine unit (GTU) of GTK 10-4, GTN-16, GT-100-750 type and other critical parts of drive turbines with operating life measured in tens of thousands of hours. Influence of long-term operation on EI 893 alloy structure and its physico-mechanical properties is considered in detail in [1-3].

Experience of PWI work on deposition of protective condensed coatings on working blades of energy turbines of peak power, made from EI 893 VD alloy, and application in this process of RHT, accepted by the enterprises of FSU Ministry of Power Engineering, allowed realization of a similar mode of reconditioning of GTK 10-4 unit working blades made from the same alloy.

Selected and approved mode of three-stage heat treatment is applied many times in reconditioning EI 893 alloy blades after different operating periods. However, under the conditions of saving the energy resources and in order to lower the cost of reconditioning repair of working blades, a decision was taken to optimize (simplify) the modes of EI 893 alloy heat treatment with preservation of all the properties and operational reliability of GTK 10-4 HPT and LPT items in further operation.

Materials and experimental procedure. «Paton Turbine Technologies» Ltd. performed assessment of repairability of four sets of HPT working blades and three sets of LPT working blades (564 pcs all together) after different periods of operation in GTK 10-4 unit. Blades with a large number of defects were selected from each set (one from each set) for cutting up and conducting comprehensive metallographic examination, both after operation and after various kinds of RHT. Samples from blade edges, cut-off before building-up and from the root were used for performance of research of impeller sets of EI 893 alloy working blades (HPT + LPT).

The structure of metal of GTK 10-4 working blades was studied using the techniques of optical and scanning electron microscopy, tensile mechanical testing at 20 and $750{ }^{\circ} \mathrm{C}$ in air, measurement of metal hardness and microhardness in the blade root and airfoil. Microstructural examination of the samples was performed in electron microscope CamScan with energy-dispersive X-ray microanalyzer Energy 200 (with INCA software). Microhardness of the base in different states was determined with application of Micro-Duromat 4000E instrument at $0.5 \mathrm{~N}$ load, and Brinell hardness was measured in TSh-2M instrument.

RHT of blades and samples was performed in laboratory SNV furnace and industrial Abar furnace at residual gas pressure not higher than $1 \cdot 10^{-4}$ Torr.

Sample testing for uniaxial tension was conducted in upgraded rigid-type R-0.5 machine, and dual cantilever load cell was used as force measure device. Force measure device was pre-calibrated using reference dynamometer of the Chamber of Weights and Measures. Tension chart was recorded in $P-\tau$ coordinates (kg-min) by KSP-4 recorder.

Results and discussion. As is known, prolonged operation of working blades results in essential changes of structural-phase state base material, i.e. its degradation takes place. This is manifested in the change of both grain structure, and fine $\left(\gamma+\gamma^{\prime}\right)$ structure of the alloy, running of phase transformations, etc. Operational ageing leads to lowering of fatigue resistance (endurance limit) of blade metal, as, consequently, reliability of operation of the turbine unit as a whole.

For instance, lowering of fatigue properties (by $20 \%$ ) in GTK 10-4 working blades from EI 893 alloy is observed after $40,000-60,000 \mathrm{~h}$ of operation at temperature of $630-670{ }^{\circ} \mathrm{C}$, which is the result of microstructural changes in base alloy. Thus, the structural factor predominates during operation of EI 893 alloy working blades: quantitative transformations of some alloy components as a result of material ageing at exposure to high-temperature gas flow and stresses developing in the parts.

Metallographic investigations of initial samples cut out of seven working blades (after different operating time) consisted in determination of alloy chemical composition (including carbon content), evaluation of grain structure; measurement of hardness and

Table 1. Some characteristics of EI 893 alloy of GTK 10-4 working blades after undetermined operating period in different HPT and LPT sets

\begin{tabular}{|c|c|c|c|c|c|c|c|}
\hline \multirow[b]{2}{*}{ Blade number } & \multirow[b]{2}{*}{ Blade type } & \multirow[b]{2}{*}{ Grain point } & \multicolumn{2}{|c|}{ Characteristics of strengthening $\gamma^{\prime}$-phase } & \multirow[b]{2}{*}{$\begin{array}{c}\text { Hardness } H B, \\
\text { MPa }\end{array}$} & \multirow{2}{*}{$\begin{array}{c}\text { Micro- } \\
\text { hardness } H_{\mu} \text {, } \\
\text { MPa }\end{array}$} & \multirow[b]{2}{*}{$\begin{array}{c}\text { Carbon } \\
\text { content, wt.\% }\end{array}$} \\
\hline & & & $\begin{array}{c}\text { Volume } \\
\text { fraction, } \%\end{array}$ & $\begin{array}{l}\text { Particle } \\
\text { size, } \mu \mathrm{m}\end{array}$ & & & \\
\hline 0084 & RL 1 st TVD & $2-4$ & 7 & $0.05-0.17$ & 2058 & 3017 & 0.040 \\
\hline 0103 & RL 1 st TVD & $2-3$ & $8-9$ & $0.02-0.16$ & 2342 & 3518 & 0.051 \\
\hline 0240 & RL 1 st TVD & 2 & $7-8$ & $0.05-0.18$ & 2165 & 2998 & 0.046 \\
\hline 0285 & RL 1 st TVD & $2-3$ & $10-11$ & $0.01-0.03$ & 2264 & 3519 & 0.043 \\
\hline 0369 & RL 2 st TVD & 3 & $4-5$ & $0.01-0.10$ & 2244 & 3447 & 0.042 \\
\hline 0430 & RL 2 st TVD & 4 & $7-8$ & $0.05-0.10$ & 2957 & 3947 & 0.062 \\
\hline 0760 & RL 2 st TVD & 3 & $8-9$ & $0.02-0.10$ & 2999 & 4040 & 0.038 \\
\hline
\end{tabular}



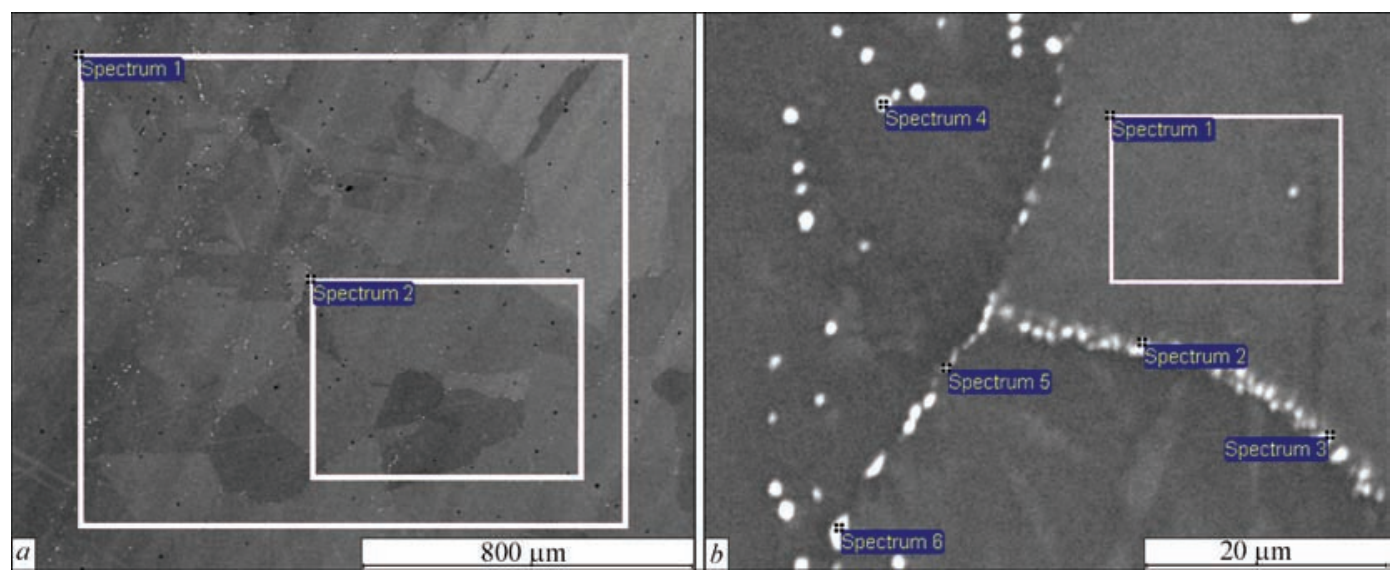

Figure 1. Regions of EDXA performance over sectional area of the sample fragment (a) and locally on phases on triple boundary of EI 893 alloy after operation $(b)$

microhardness, evaluation of fine $\left(\gamma+\gamma^{\prime}\right)$-structure, determination of phase composition and distribution of secondary phases (Table 1). It was established that chemical composition of seven blades from different sets fully corresponded to specified alloy EI 893 (KhN65VMTYu), wt.\%: Ni-(15-17)Cr-(3.5-4.5)Mo(8.5-10)W-(1.2-1.6)Al-(1.2-1.6)Ti-0.6Mn-0.6Si$<3 \mathrm{Fe}-<0.07 \mathrm{C}$, in particular for carbon (Table 2; Figure 1, a).

At in-coming inspection of working blade sets after operation at working temperatures, erosion-corrosion damage, nicks, dents, etc. were found on the rejected blade surface. Blade material did not have cracks, but structure of blades after different operating periods was characterized by $2-4$ point grain $(78-177 \mu \mathrm{m})$ to GOST 5639-82, and difference in material grain size was also observed (Figure 2, $a, c$ ).

After long-term operation of blades (about $60,000 \mathrm{~h}$ ) cracks can initiate on base alloy grain boundaries (where grains have different size) during subsequent operation, in view of different deformability of coarse and fine grains. Cracks can be of both transcrystalline and intragranular nature. Authors of [4] studied the influence of grain size on structural fatigue strength of blades (32 pcs) from EI 893 alloy, and established that the dimensional factor of grain size (from $0.5-1.0$ to $3-5 \mathrm{~mm}$ ) only slightly influences the level of fatigue strength. It was determined that at asymmetrical loading and room temperature the increase of grain size from $0.1-0.35$ to $0.4-1.5 \mathrm{~mm}$ leads to lowering of blade endurance limit by just $4.6 \%$, and this enables allowing the presence of regions with up to $1.5 \mathrm{~mm}$ grain size, in the structure of EI 893 alloy working blades for stationary GTU, without any adverse influence on item serviceability. The same authors also showed [4] that fatigue crack initiation is influenced to a greater extent by defects of mechanical origin and variation of edge rounding-off radius.

During long-term operation the level of mechanical properties of metal of working blades from EI 893 alloy is characterized by a change of ductility and strength values, compared to metal in the initial state: metal ductility decreases at simultaneous increase of $H B$ hardness and ultimate strength and yield limit. Lowering of impact toughness, notch sensitivity and fatigue properties is associated with ductility lowering. Change of mechanical characteristics is due to structural changes in the metal in operation, i.e. during operation at blade working temperature of

Table 2. Chemical composition of base alloy of GTK 10-4 I stage blades after undetermined operating period (blade 0084)

\begin{tabular}{|c|c|c|c|c|c|c|c|}
\hline Spectrum number & $\mathrm{Al}$ & $\mathrm{Ti}$ & $\mathrm{Cr}$ & $\mathrm{Ni}$ & Mo & W & $\mathrm{C}$ \\
\hline \multicolumn{8}{|c|}{ Chemical composition of EI 893 alloy after operation (airfoil) (acc. to Figure 1, a) } \\
\hline 1 & 1.29 & 1.36 & 16.37 & 67.78 & 4.52 & 8.68 & \multirow{2}{*}{$0.04^{*}$} \\
\hline 2 & 1.24 & 1.36 & 16.8 & 68.48 & 3.95 & 8.17 & \\
\hline EI 893 regular composition & $1.2-1.6$ & $1.2-1.6$ & $15-17$ & $60.9-60.6$ & $3.5-4.5$ & $8.5-10$ & $\leq 0.07$ \\
\hline \multicolumn{8}{|c|}{ Chemical composition of phases in EI 893 alloy matrix after operation (airfoil) (acc. to Figure 1, b) } \\
\hline 1 & 1.15 & 1.17 & 16.61 & 65.13 & 3.80 & 8.79 & $3.34^{* *}$ \\
\hline 2 & 0.87 & 1.23 & 14.79 & 43.37 & 10.64 & 20.60 & $8.49^{* *}$ \\
\hline 3 & 1.03 & 1.26 & 14.36 & 46.69 & 9.67 & 18.32 & $8.69^{* * *}$ \\
\hline 4 & 0.48 & 0.68 & 11.33 & 25.88 & 13.58 & 36.93 & $10.49^{* *}$ \\
\hline 5 & 1.10 & 1.23 & 15.43 & 58.52 & 5.02 & 10.92 & $7.78^{* * *}$ \\
\hline 6 & 0.46 & 0.77 & 11.68 & 25.04 & 14.64 & 36.47 & $10.94^{* *}$ \\
\hline
\end{tabular}




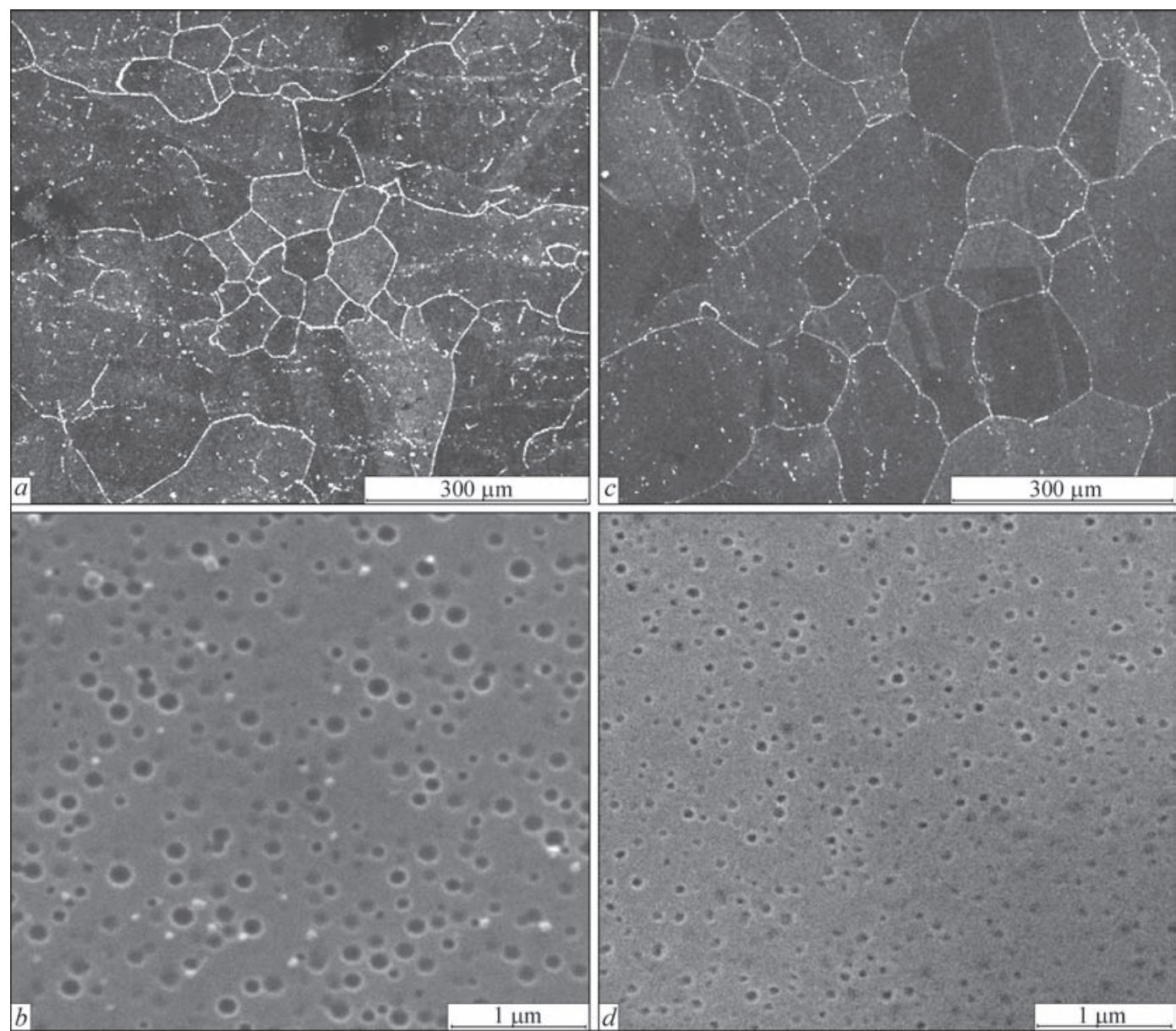

Figure 2. Micro- and macrostructure of alloy in blades $0084(a, c)$ and $0764(b, d)$ after different operating periods

$630-670{ }^{\circ} \mathrm{C}$ ageing of EI 893 alloy leads to additional precipitation and coagulation of particles of both strengthening $\gamma^{\prime}$-phase, and carbides of $\mathrm{MeC}, \mathrm{Me}_{6} \mathrm{C}$, $\mathrm{Me}_{23} \mathrm{C}_{6}$ type in the grain bulk and on the boundaries [5]. Decomposition of $\mathrm{MeC}$ and $\mathrm{Me}_{23} \mathrm{C}_{6}$ carbides can lead to formation of particles of a more complex $\mathrm{M}_{6} \mathrm{C}$ carbide. Carbide coarsening and coalescence in intergranular interlayers to $0.5-6.0 \mu \mathrm{m}$, partial fringing of the boundaries by $\gamma^{\prime}$-phase particles can have an adverse effect: reduction of blade metal relative elongation to 20-28\%. So, decrease of yield limit over $60,000 \mathrm{~h}$ of operation is equal to $250 \mathrm{MPa}$ on average, i.e. fracture toughness decreases and cracking probability rises [6].

In seven studied blades after different operation periods the structure is characterized, primarily, by irregular distribution (4-11 vol.\%) of the main strengthening phase of $0.01-0.18 \mu \mathrm{m}$ size in matrix solution volume, i.e. its partial dissolution, coagulation and running of carbide reactions, proceeding mainly on grain boundaries with further coagulation of carbide phases (Figure 2, $b, d$ ). After operation these carbide phases mainly are globular MeC carbides (based on $\mathrm{W}, \mathrm{Mo}, \mathrm{Cr}$ ), their size not exceeding $2 \mu \mathrm{m}$ (see Table 2 and Figure 1, $b$ ).
Hardness is a mechanical characteristic of material, the value of which is correlated reliably with the values of yield limit (ultimate strength) of tested material in a broad temperature range. To assess the properties of blades after long service or RHT operations, a control operation of measurement of blade metal hardness $H B$ is necessarily used, usually, on root end face in the vicinity of 1st tooth, where the part area allows producing the respective imprint by pressing down the indenter - sphere of $10 \mathrm{~mm}$ diameter with $3000 \mathrm{~kg}$ force.

Real working blades demonstrate a noticeable scatter of physico-mechanical properties by item height, whereas the blade root is not exposed to any significant temperature impact in operation, compared to its profile part (i.e. root metal can characterize the alloy properties in the initial state). As is seen from Table 1, the most probable hardness values of EI $893 \mathrm{VD}$ alloy in blades with different operating times are in the range of $H B$ 2058-2999, and are indicative of the fact that $60 \%$ of all the studied blades have hardness close to that of initial material (HB 2170-2770) and correspond to the level of $H B$ values earlier obtained on GT-100 and GTK 10-4 working blades, that is in agreement with the data of authors of [6-8]. 
In the case of working blades 0430 and 0760, EI 893 alloy hardness was equal to HB 2957-2999. These rather high hardness values and slight increase of microhardness were indicative of development of metal ageing process, and in the case of blade 0760 of structure overageing in operation with precipitation of ultrafine phase of $0.01-0.03 \mu \mathrm{m}$ (see Table 1). Quite high hardness values could also be determined by stamping deformation texture and inherited texture of recrystallization and carbide striation in an actual item.

Structural changes in base alloy as a result of longterm operation are reversible. It requires application of RHT in vacuum, which restores physico-mechanical properties of working blade metal (in particular, EI 893 alloy) to the level, corresponding to initial state (before operation).

Application of three-stage heat treatment of working blades of power GTU HPT at some time (1980s) provided high operating reliability of peak power turbines even with gas temperature increase. RHT mode did not lower the strength properties of metal, including structural endurance of blades and provided a high level of base alloy properties, not differing from (or even exceeding) the level of metal properties after standard multistage heat treatment after billet stamping, namely: $1020^{\circ} \mathrm{C}, 2 \mathrm{~h}+1160{ }^{\circ} \mathrm{C}, 3 \mathrm{~h}$, air + $1000^{\circ} \mathrm{C}, 4 \mathrm{~h}$, air $+900{ }^{\circ} \mathrm{C}, 8 \mathrm{~h}$, air $+850^{\circ} \mathrm{C}, 15 \mathrm{~h}$, air.

RHT of blades after operation is traditionally performed in vacuum furnaces with forced cooling by argon in the following mode: heating to $1040{ }^{\circ} \mathrm{C}, 4 \mathrm{~h}$, cooling to $300{ }^{\circ} \mathrm{C}$, heating to $900{ }^{\circ} \mathrm{C}, 8 \mathrm{~h}$, cooling to $300+820^{\circ} \mathrm{C}, 15 \mathrm{~h}$. Cooling rate should be not lower than $12 \mathrm{deg} / \mathrm{min}$ in high-temperature cooling section (to $650^{\circ} \mathrm{C}$ ).

Earlier studies of reference blades of industrial batches of HPT and LPT I and II stages (EI 893 alloy) of GT-100-750 power unit after three-stage RHT showed that at $20^{\circ} \mathrm{C}$ the main test results for yield limit fall within the range of 500-600 MPa, and ultimate strength exceeds $900 \mathrm{MPa}$ (reaching $1040 \mathrm{MPa}$ ), elongation at fracture is more than $20 \%$ with $30-40 \%$ maximum of values. A certain scatter of values was observed for impact toughness with a maximum in the range of $60-80 \mathrm{~J} / \mathrm{cm}^{2}$.

To recover the service properties of blades from EI 893 alloy, the authors of [6] proposed a simplified (two-stage) RHT schematic: annealing in argon at $1050{ }^{\circ} \mathrm{C}(2 \mathrm{~h})$, rapid cooling, heating to $850{ }^{\circ} \mathrm{C}$, soaking for $5 \mathrm{~h}$, and cooling by argon.

No significant change of alloy phase composition occurs as a result of RHT. Metal $\mathrm{M}_{6} \mathrm{C}$ remains the main carbide phase. Quantity of strengthening $\gamma^{\prime}$-phase somewhat decreases and corresponds to initial state (before operation). After RHT, blade metal hardness level decreases, and ductile characteristics increase, reaching initial values. Authors of [7] also considered two-stage RHT after operation $\left(1050{ }^{\circ} \mathrm{C} 3 \mathrm{~h}\right.$, cooling in air, and subsequent ageing at $850^{\circ} \mathrm{C}(12 \mathrm{~h})$, cooling in air) and studied EI 893 alloy mechanical properties after it. It was shown that two-stage treatment provides optimum values of structural and mechanical properties (so, relative elongation is equal to $36 \%$ at ultimate strength of $920 \mathrm{MPa}$ ).

In connection with the need for build-up welding of blade end seal, the blades after operation should be subjected to austenitizing (vacuum annealing) at $1160{ }^{\circ} \mathrm{C}$ and residual gas pressure of $1 \cdot 10^{-4}$ Torr in the working chamber. Blade material structure as a result of annealing becomes close to single-phase one and acquires the ability to be welded in a satisfactory manner without crack initiation. After welding and machining of built-up sections, the parts are subjected to RHT by $1040+900+820{ }^{\circ} \mathrm{C}$ mode. Therefore, GTK 10-4 working blades, coming in for repair and reconditioning after various periods of operation, should be subjected to four-stage heat treatment, including primary homogenizing before building-up (welding) and three-stage ageing. Three RHT variants (with different duration of stages) were considered in order to select and optimize the modes:

- $1160+1040+900+820^{\circ} \mathrm{C}$ (four-stage);

- $1160+900+820^{\circ} \mathrm{C}$ (three-stage);

- $1040+820^{\circ} \mathrm{C}$ (two-stage).

All the samples, cut out of seven sectioned blades after different operation periods, were taken through the stages of one of the three heat treatment variants. Changes in base material structure were studied after each RHT stage. So, after homogenizing at $1160{ }^{\circ} \mathrm{C}$, grain coarsening, fine grain boundary dissolution and partial dissolution of coarse grain boundaries were observed. In such a mode not only the main strengthening $\gamma^{\prime}$-phase, but also carbide phases in the grain middle and on their boundaries dissolve to the maximum degree (Figure 3,a). After homogenizing, the secondary phases are represented by dispersed particles $(1-2 \mu \mathrm{m})$ of stable carbide phases of MeC type based on tungsten and molybdenum (Table 3; Figure $4, a$ ).

$\mathrm{Me}_{6} \mathrm{C}$ carbide forms at $1030{ }^{\circ} \mathrm{C}$, so that at heat treatment at close temperature it is exactly the main carbide phase, that lowers the possibility of carbide reactions running during subsequent operation (this carbide is stable up to $1250{ }^{\circ} \mathrm{C}$ and in high-temperature alloys it can form from the melt). After long-term operation at higher temperatures of operational ageing (for instance, blade airfoil), this carbide can transform into $\mathrm{Me}_{12} \mathrm{C}-\eta$ carbide, belonging to the same 


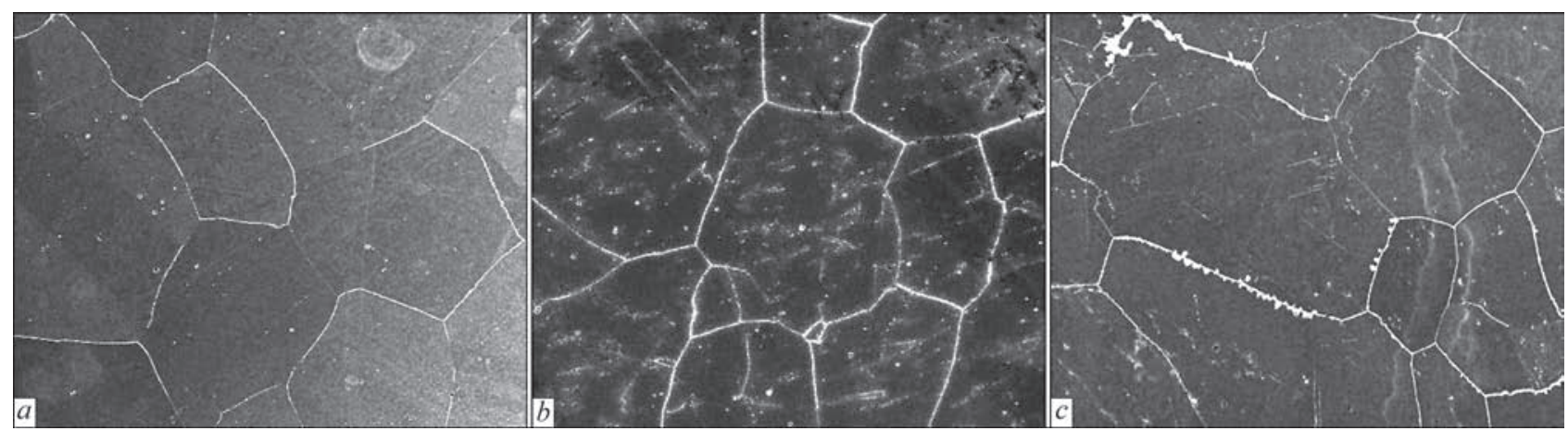

Figure 3. Macrostructure $(\times 100)$ of alloy on blades after different RHT stages: $a-1160 ; b-1160+1040 ; c-1160+1040+900{ }^{\circ} \mathrm{C}$
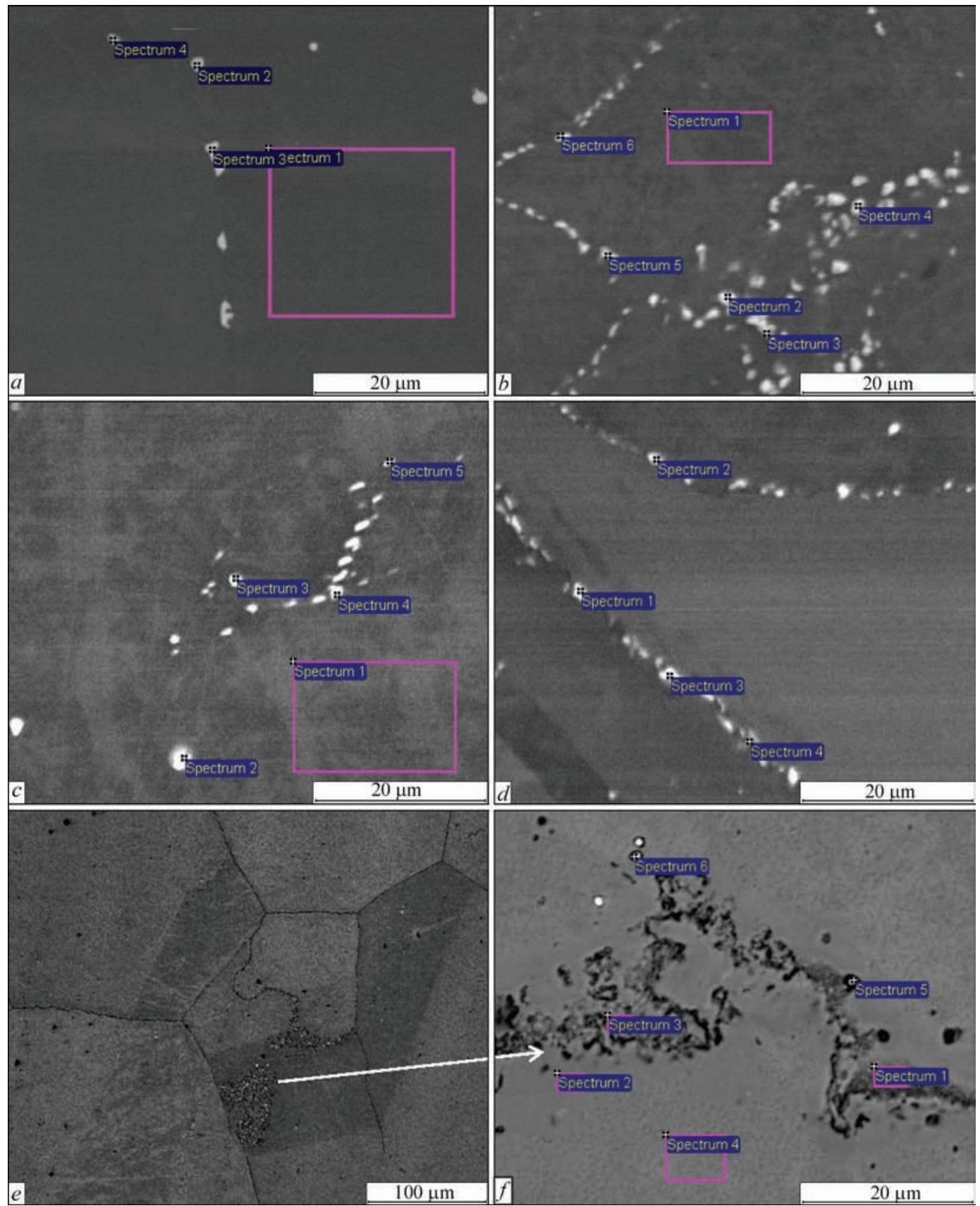

Figure 4. Regions of determination of chemical composition of EI 893 alloy structural components after different stages of heat treatment: $a-1160 ; b-1160+1040 ; c-1040+820 ; d-1160+1040+900+820 ; e, f-1160+900+820^{\circ} \mathrm{C}$ 
Table 3. Chemical composition of phases in matrix of EI 893 alloy after different heat treatment stages

\begin{tabular}{|c|c|c|c|c|c|c|c|c|}
\hline Spectrum number & C & $\mathrm{Al}$ & $\mathrm{Ti}$ & $\mathrm{Cr}$ & $\mathrm{Fe}$ & $\mathrm{Ni}$ & Mo & $\mathrm{W}$ \\
\hline \multicolumn{9}{|c|}{ After homogenizing at $1160{ }^{\circ} \mathrm{C}$ (acc. to Figure $4, a$ ) } \\
\hline 1 & 3.27 & 1.48 & 1.69 & 15.81 & 0.05 & 64.95 & 4.32 & 8.44 \\
\hline 2 & 9.91 & 0.24 & 0.45 & 16.68 & 0.24 & 11.80 & 20.11 & 40.57 \\
\hline 3 & 9.37 & 0.12 & 0.69 & 15.53 & 0.24 & 19.72 & 17.52 & 36.81 \\
\hline 4 & 8.64 & 0.64 & 0.72 & 17.36 & 0.27 & 21.74 & 18.34 & 32.29 \\
\hline \multicolumn{9}{|c|}{ After homogenizing at $1160+1040{ }^{\circ} \mathrm{C}$ (acc. to Figure $\left.4, b\right)$} \\
\hline 1 & 3.47 & 1.25 & 1.39 & 15.55 & - & 65.17 & 3.72 & 9.44 \\
\hline 2 & 9.04 & 0.67 & 0.93 & 16.31 & - & 38.37 & 11 & 23.68 \\
\hline 3 & 8.90 & 0.60 & 0.99 & 13.12 & - & 40.92 & 10.59 & 24.89 \\
\hline 4 & 7.25 & 1.32 & 1.34 & 16.18 & - & 55.71 & 5.29 & 12.90 \\
\hline 5 & 7.64 & 1.12 & 1.30 & 15.84 & 0.36 & 56.65 & 4.93 & 12.16 \\
\hline 6 & 7.89 & 1.32 & 1.37 & 15.51 & 0.35 & 61.85 & 3.56 & 8.15 \\
\hline \multicolumn{9}{|c|}{ After heat treatment at $1040+820^{\circ} \mathrm{C}$ (acc. to Figure $4, c$ ) } \\
\hline 1 & 2.95 & 1.11 & 1.10 & 15.91 & - & 65.63 & 3.68 & 9.61 \\
\hline 2 & 11.59 & - & 0.65 & 2.10 & - & 29.22 & 48.11 & 8.34 \\
\hline 3 & 9.41 & 0.60 & 0.88 & 12.50 & - & 34.29 & 12.33 & 29.99 \\
\hline 4 & 7.25 & 0.42 & 0.71 & 12.37 & - & 28.50 & 15.03 & 35.73 \\
\hline 5 & 5.66 & 1.10 & 1.31 & 15.29 & - & 61.95 & 3.74 & 10.95 \\
\hline \multicolumn{9}{|c|}{ After heat treatment at $1160+1040+900+820^{\circ} \mathrm{C}$ (acc. to Figure $4, d$ ) } \\
\hline 1 & 9.83 & 0.45 & 1.06 & 12.79 & 0.47 & 33.13 & 12.55 & 29.72 \\
\hline 2 & 6.09 & 1.02 & 1.33 & 15.24 & 0.54 & 64.29 & 3.76 & 7.73 \\
\hline 3 & 5.14 & 1.24 & 1.60 & 16.10 & 0.42 & 55.31 & 6.28 & 13.91 \\
\hline 4 & 6.14 & 2 & 1.87 & 23.11 & 0.16 & 51.20 & 5.65 & 9.86 \\
\hline \multicolumn{9}{|c|}{ After heat treatment at $1160+900+820^{\circ} \mathrm{C}$ (acc. to Figure $4, f$ ) } \\
\hline 1 & 8.17 & 0.65 & 0.87 & 19.74 & 1.56 & 56.69 & 3.84 & 8.47 \\
\hline 2 & 4.27 & 0.98 & 1.08 & 16.29 & 1.85 & 63.86 & 3.18 & 8.48 \\
\hline 3 & 6.74 & 0.65 & 0.73 & 23.16 & 1.57 & 52.96 & 4.55 & 9.63 \\
\hline 4 & 3.70 & 1.09 & 1.12 & 15.38 & 1.65 & 64.07 & 3.76 & 9.23 \\
\hline 5 & 3.18 & 0.19 & 0.57 & 22.77 & 1.02 & 34.20 & 11.69 & 26.38 \\
\hline 6 & 4.46 & 0.68 & 0.98 & 17.79 & 1.56 & 57.95 & 4.72 & 11.86 \\
\hline
\end{tabular}

class of stable carbides. Thus, after high-temperature ageing stage, $\mathrm{Me}_{6} \mathrm{C}$ and primary $\mathrm{MeC}$ carbides are the secondary strengthening phases in EI 893 alloy (see Table 3; Figure 4, b). Partial recrystallization of material proceeds at the same heat treatment stage (see Figure 3, $b$ ).

Chromium-based $\mathrm{Me}_{23} \mathrm{C}_{6}$ carbide starts precipitating at $840-925^{\circ} \mathrm{C}$ by $\mathrm{MeC}+\gamma \rightarrow>\mathrm{Me}_{23} \mathrm{C}_{6}+\gamma^{\prime}$ reaction on grain boundaries, where diffusion and phase transformations, respectively, proceed more readily. This carbide precipitates during multistage ageing on grain boundaries (except for $\mathrm{Me}_{6} \mathrm{C}$, the particle size of which is $0.3-0.5 \mu \mathrm{m})$. This carbide is rather unstable and in operation at $550-750{ }^{\circ} \mathrm{C}$, it undergoes transformation on grain boundaries by the reaction of $\mathrm{Me}_{23} \mathrm{C}_{6} \rightarrow \mathrm{Me}_{6} \mathrm{C} \rightarrow \mathrm{Me}_{12} \mathrm{C}$. After formation of the last carbides, their coagulation takes place (up to $1.0-1.5 \mu \mathrm{m})$. Temperature of complete dissolution of unstable chromium carbide $\mathrm{Me}_{23} \mathrm{C}_{6}$ is equal to 900 $1040{ }^{\circ} \mathrm{C}$.

After heat treatment by the mode of $1160+1040+$ $+900{ }^{\circ} \mathrm{C}$ the base structure shows local thickening of grain boundaries with formation of sequences or colonies of $\mathrm{Me}_{23} \mathrm{C}_{6}$ carbide phases of more than 3-5 $\mu \mathrm{m}$ size (see Figure 3, $c$ ).
Certain RHT modes (homogenizing and ageing temperatures) can promote formation of various qualitative ratios of structural phases in the matrix solution. Secondary phases of EI 893 alloy usually amount to 1.1-1.3 vol.\% and are $\mathrm{MeC}, \mathrm{Me}_{23} \mathrm{C}_{6}, \mathrm{Me}_{6} \mathrm{C}$ carbides and $\mathrm{Me}_{3} \mathrm{~B}_{2}$ and $\mathrm{Me}_{5} \mathrm{~B}_{6}$ borides, influencing the alloy mechanical properties, particularly distribution morphology. It is obvious that in order to create alloy structure closer to equilibrium one after RHT, it is necessary to ensure formation of stable phases of $\mathrm{MeC}$ and $\mathrm{Me}_{6} \mathrm{C}$ type based on tungsten and molybdenum, and minimization of chromium carbide phases. The higher the homogenizing temperature, the higher is the temperature of stable phase formation. So, only stable $\mathrm{Me}_{6} \mathrm{C}$ and $\mathrm{Me}_{3} \mathrm{~B}_{2}$ phases are found after homogenizing at $1200{ }^{\circ} \mathrm{C}$, which are preserved after long-term operation, irrespective of variants of subsequent heat treatment, that characterizes stable state of EI 893 alloy. Considered three modes of recovery heat treatment of two, three and four stages, eventually lead to formation of significantly different base structures (Figure 4, $c, d$, $f$ and Figure 5).

So, at two-stage RHT base macrostructure consists, mainly, of equiaxed grains of 2-4 point with thin grain boundaries (Figure 5, $a, b$ ). Here, the mi- 


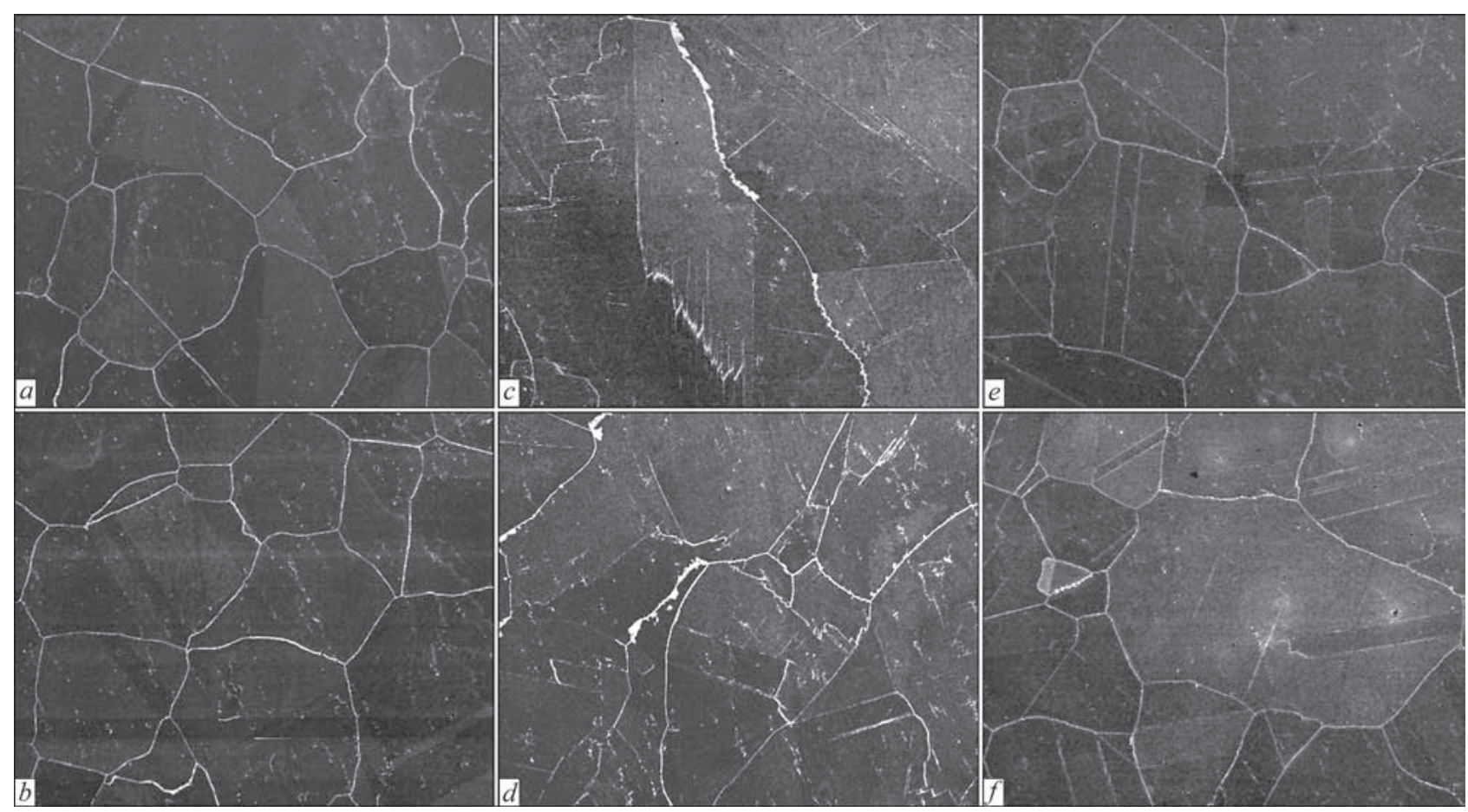

Figure 5. Microstructure $(\times 100)$ of EI 893 alloy on sample 2040 after heat treatment at $1040+820(a, b), 1160+900+820(c, d)$ and $1160+1040+900+820^{\circ} \mathrm{C}(e, f)$

crostructure is a homogeneous solid solution with discrete precipitations of globular carbide phases of $\mathrm{Me}_{6} \mathrm{C}$ and $\mathrm{MeC}$ type (see Figure 4, $c$ and Table 3). Primary stable $\mathrm{MeC}$ carbides are most often located inside and on grain boundaries and correspond to complex carbide of II group (W, Mo, Cr)C. At not more than $1 \mu \mathrm{m}$ grain size and discrete distribution through the grain, particles of this carbide phase have no adverse influence on metal mechanical characteristics.

At three-stage RHT mode (without $1040{ }^{\circ} \mathrm{C}$ annealing), material structure clearly demonstrates presence of both grains of different size, and precipitates of a large amount of carbide phases on grain boundaries, slip bands and stacking faults (Figure $5, c, d$ ). On the one hand, at heat treatment at $1160+900+820^{\circ} \mathrm{C}$ only $\mathrm{Me}_{23} \mathrm{C}_{6}$ carbide is found in the metal, the discrete particles of which are of 0.3-0.4 $\mu \mathrm{m}$ size, and we could speak about a high level of ductility and impact toughness at $20^{\circ} \mathrm{C}$ (exceeding the level after stepped HT). These carbide phases, however, are not an effective obstacle to intergranular slipping. Moreover, these phases also form carbide sequences and clusters (colonies) of more than $5 \mu \mathrm{m}$ size in the alloy matrix. Coarsening and coalescence of $\mathrm{Me}_{23} \mathrm{C}_{6}$ carbides up to $5 \mu \mathrm{m}$ in intergranular interlayers, partial fringing of boundaries by $\gamma^{\prime}$-phase particles can have an adverse influence on fracture toughness lowering and can increase the probability of crack initiation. Lowering of impact toughness, notch sensitivity and fatigue properties is related to ductility lowering (see Figure $4, f$ and Table 3).
Standard four-stage RHT mode leads to formation of a structure with different grain size and slip bands, the presence of which can lead later on to microcrack initiation and propagation, and to fracture at fatigue testing (Figure 5, e f). Secondary phases precipitate, mainly, on grain boundaries, and consist of carbides of three types, namely $\mathrm{MeC}, \mathrm{Me}_{23} \mathrm{C}_{6}, \mathrm{Me}_{6} \mathrm{C}$ (see Table 3 and Figure 4, $d$ ).

The main strengthening phase of EI 893 alloy is $\gamma^{\prime}$-phase precipitating during prolonged ageing in temperature range of 950 to $550{ }^{\circ} \mathrm{C}$. Its amount depends on ageing temperature and is equal to $9 \%$ at $850,5 \%$ at $900,2 \%$ at 950 and $16 \%$ at $650-670{ }^{\circ} \mathrm{C}$ (maximum quantity) [9]. Formation of equilibrium $\gamma^{\prime}$ phase proceeds at temperature of $650{ }^{\circ} \mathrm{C}$ after ageing for $1000 \mathrm{~h}$. During investigations it was found that RHT application for used blades promoted dissolution of coarsened $\gamma^{\prime}$-phase and subsequent precipitation of regular fine-dispersed strengthening phase. Here, application of two-stage heat treatment promoted precipitation of a larger amount of $\gamma^{\prime}$-phase: 8-10\% (compared to 7-8 \% at four-stage RHT) with finer particles of 0.21-0.06 $\mu \mathrm{m}$ (Figure 6).

Hardness, being quite an important characteristic of working blade material, is determined, primarily, by structural state of EI 893 alloy, namely, grain size, quantity and morphology of secondary (most probably) boundary phases, determined by the number of worked hours. Hardness graphs clearly show the structural changes, occurring at different RHT stages (Figure $7, a, b)$. So, during homogenizing at $1160{ }^{\circ} \mathrm{C}$ dis- 

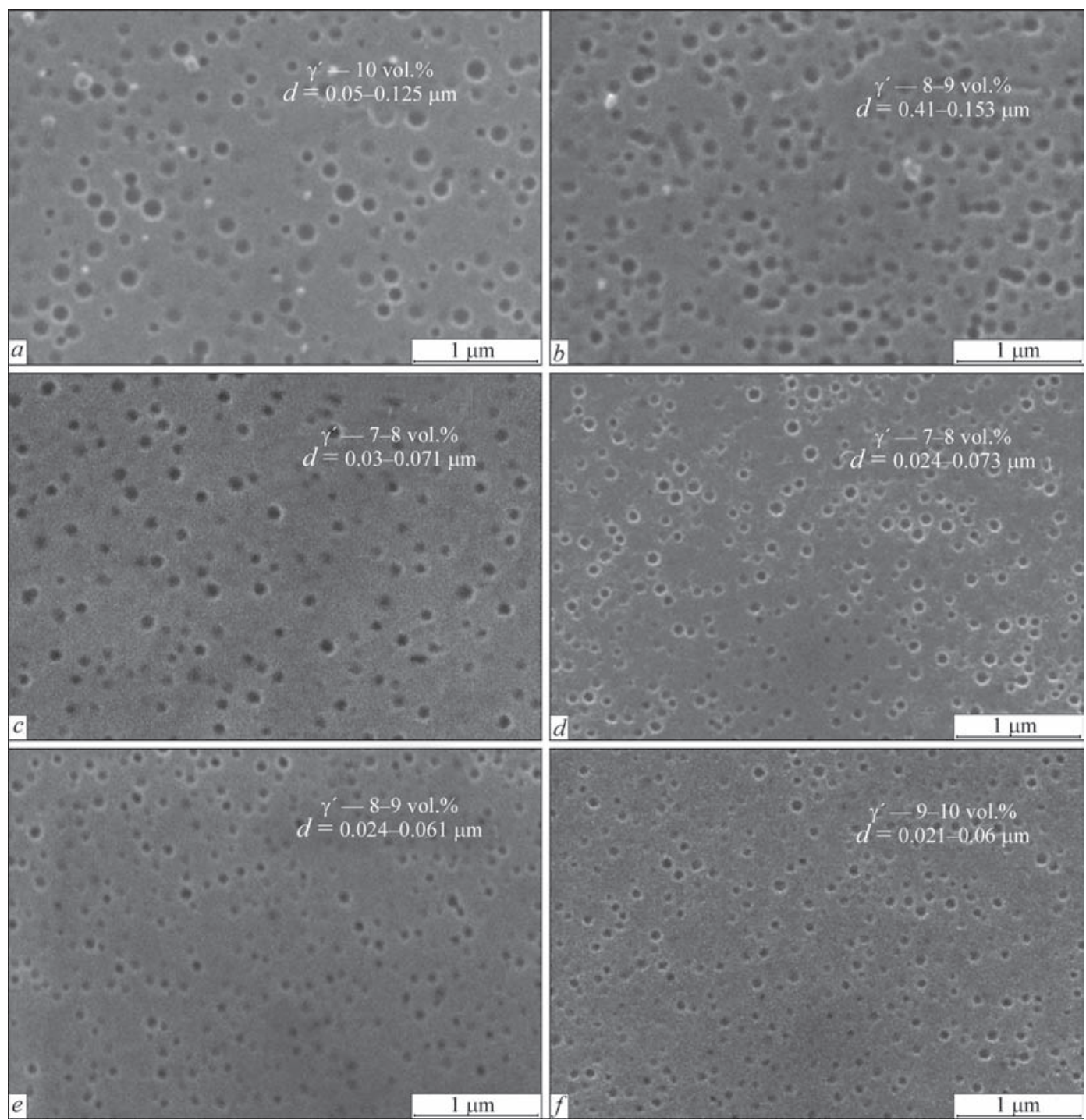

Figure 6. Microstructure of EI 893 alloy after operation $(a, b)$, after four- $(c, d)$ and two-stage RHT $(e, f)$ in blades $0084(a, c, e)$ and $0103(b, d, f)$

solution of the main strengthening $\gamma^{\prime}$-phase and most of the secondary carbide-boride phases (particularly, on grain boundaries) takes place, leading to definite lowering of material hardness. Partial recrystallization of metal (grain refinement), precipitation and stabilization of $\mathrm{Me}_{6} \mathrm{C}$ type carbides proceed at subsequent annealing at $1040{ }^{\circ} \mathrm{C}$, leading to increase of material hardness. At subsequent ageing stages, namely at 900 and $820^{\circ} \mathrm{C}$, secondary and main strengthening phases precipitate, which influence material hardness increase.

Graphs of hardness measured at different RHT stages, for each of seven blades studied, are indicative of lowering of its values at high-or low-temperature homogenizing and subsequent increase during ageing. After each of the three RHT modes, blade hardness finally reached the base level of values -2100 $2700 \mathrm{MPa}$, that confirmed recovery of item material technological properties.

Microhardness, mainly, is the characteristic of grain body strengthening by secondary phases and main strengthening $\gamma^{\prime}$-phase. Microhardness graphs for all the samples suggest that homogenizing leads to complete dissolution of the strengthening phase and majority of secondary phases in the matrix, while $1040{ }^{\circ} \mathrm{C}$ temperature is that of partial dissolution of $\gamma^{\prime}$-phase and complete dissolution of unstable boundary chromium carbides of $\mathrm{Me}_{23} \mathrm{C}_{6}$ type, as well as stabilization temperature of $\mathrm{Me}_{6} \mathrm{C}$ carbide, leading to microhardness increase. Subsequent two-stage ageing causes a more complete increase of the amount of $\gamma^{\prime}$-phase and subsequent increase of $H V$ values (Figure $7, c, d)$.

Presented graphs and microstructures confirm the correctness of judgments about structural regeneration of the alloy after RHT. So, a certain reduction of difference in grain size (mainly, grain point of 2-4), lowering of ductility and reduction of dimensions of carbide phases in intergranular interlayers, and uniform precipitation of the strengthening phase, are observed. Application of two-stage RHT mode led to absence of 

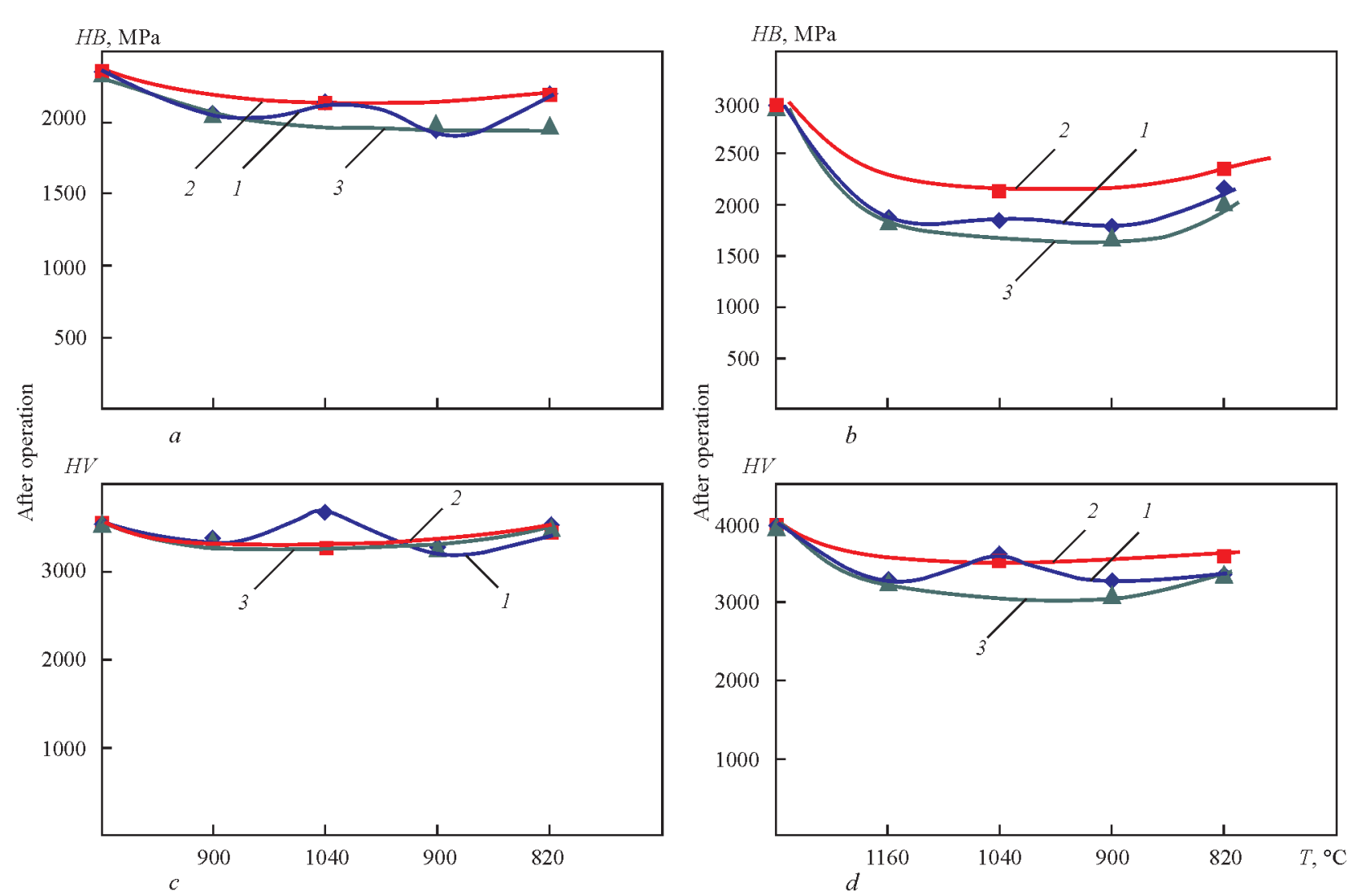

Figure 7. Hardness $H B(a, d)$ and microhardness $H V(c, d)$ of EI 893 alloy in blades $0103(a, c)$ and $0430(b, d)$ after different heat treatment stages: $1-1160+1040+900+820 ; 2-1040+820 ; 3-1160+900+820{ }^{\circ} \mathrm{C}$

more than $5 \mu \mathrm{m}$ clusters of $\mathrm{Me}_{23} \mathrm{C}$ carbides (characteristic for RHT with $900{ }^{\circ} \mathrm{C}$ stage) and non-uniformity of distribution and diversity of secondary phases, as in the case of three- and four-stage RHT mode.

So, for instance, for blade 0430 from the set of working blades of GTK 10-4 II stage, the quite high hardness HB 2957 of EI 893 alloy after operation decreases to normal level of $2300 \mathrm{MPa}$ as a result of RHT (Figure 7, $b$ ).

RHT leads to lowering of base alloy hardness (increase of ductility) due to redistribution of impurities from grain boundaries into matrix solution and reverse dissolution of embrittling phases, precipitated on grain boundaries as a result of interstitial impurity segregation and unfavourable carbide transformations in the alloy in turbine blade operation, as well as partial dissolution of the strengthening $\gamma^{\prime}$-phase.

Selection of heat treatment mode was controlled by performance of mechanical testing of qualification samples, cut out of blade airfoil and root part after long-term operation. Sample testing for uniaxial tension was applied to assess mechanical properties (strength, ductility) of EI 893 alloy after operation and possibility of their improvement after RHT.

Tables 4 and 5 summarize the results of testing samples of MI-9 and MI-12 type (according to PWI specification), cut out of the roots and lower part of airfoil of HPT I stage working blades, after opera- tion in different regions (including reference-blades 86 and 016 from GTK 10-4 BKF-05 blade set after $57,373 \mathrm{~h}$ of operation).

Results of tensile mechanical testing were fully consistent with TU 14-1-2662-79 (or TU 108-02005) for EI 893 VD alloy. A certain lowering of alloy ductile properties $(\delta$ and $\psi$ ) was noted at simultaneous increase of hardness $H B$, yield limit $\sigma_{0.2}$ and strength $\sigma_{t}$ as a result of operation (see Tables 4 and 5). During RHT performance low-temperature ductility (up to $\delta=35.6 \%$ ) increased simultaneously with lowering of blade metal strength and hardness. Physico-mechanical properties of EI 893 alloy exceeded those of initial EI 893 VD alloy before mounting the blades in the turbine (according to TU). Obtained results demonstrated the practically complete coincidence of mechanical properties of blade metal after operation and after RHT by the data of testing performed in 2004-2005 and given in the report [9].

Results of tensile testing showed a slight deviation of physico-mechanical properties of metal of blade profile part from those of root metal, in view of different temperature conditions of operation, i.e. higher temperature through the airfoil.

Strength and ductility properties at increased temperature of $750{ }^{\circ} \mathrm{C}$ are quite important physico-mechanical characteristics of the alloy for working blades (see Table 5). High-temperature testing was 
Table 4. Mechanical properties of metal of GTK $10-4$ working blades at $20^{\circ} \mathrm{C}$ after operation and RHT in vacuum

\begin{tabular}{|c|c|c|c|c|c|}
\hline Blade number & Analysis location & $\sigma_{0.2}, \mathrm{MPa}$ & $\sigma_{\mathrm{t}}, \mathrm{MPa}$ & $\delta, \%$ & $\psi, \%$ \\
\hline \multicolumn{6}{|c|}{ After $57,000 \mathrm{~h}$ of operation } \\
\hline \multirow{2}{*}{86} & Root lower tooth & $\begin{array}{l}606.2 \\
629.4\end{array}$ & $\begin{array}{c}1073.5 \\
1107\end{array}$ & $\begin{array}{c}33.2 \\
36\end{array}$ & $\begin{array}{c}37 \\
35.8\end{array}$ \\
\hline & Root middle tooth & $\begin{array}{l}629.4 \\
640 ?\end{array}$ & 1100 & 33.6 & 30.5 \\
\hline \multirow[b]{2}{*}{66} & \multirow{2}{*}{ Airfoil front part } & 629 & 1103 & $\begin{array}{l}32.4 \\
28.2\end{array}$ & $\frac{30.5}{31}$ \\
\hline & & 692 & 1050 & 28.5 & 31.7 \\
\hline \multicolumn{6}{|c|}{ After 3-stage RHT } \\
\hline \multirow{5}{*}{122} & \multirow{2}{*}{ 3rd tooth } & 575 & 981 & 36 & 23.4 \\
\hline & & 531.7 & 987.5 & 41.3 & 30.5 \\
\hline & \multirow{3}{*}{ 2nd tooth } & 542.6 & 970 & 37.5 & 27.6 \\
\hline & & 531.7 & 955 & 34.8 & 30.5 \\
\hline & & 543 & 972 & 33 & 30.5 \\
\hline \multirow{5}{*}{123} & \multirow{2}{*}{ 3rd tooth } & 578.4 & 1032 & 40 & 28.8 \\
\hline & & 602.2 & 1025 & 37.6 & 27 \\
\hline & \multirow{3}{*}{ 2nd tooth } & 580.3 & 1011.6 & 33.8 & 30 \\
\hline & & 573 & 1003 & 31.2 & 23.8 \\
\hline & & 547.4 & 991.7 & 32.3 & 32.3 \\
\hline \multirow{5}{*}{151} & \multirow{2}{*}{ 3rd tooth } & 616.4 & 1107 & 34.8 & 30.5 \\
\hline & & 662.3 & 1096 & 38.5 & 35.5 \\
\hline & \multirow{3}{*}{ 2nd tooth } & 629.4 & 1076.5 & 36.7 & 27 \\
\hline & & 621.3 & 1083.4 & 33.2 & 26.9 \\
\hline & & 629.4 & 1096 & 33.3 & 32.8 \\
\hline \multicolumn{6}{|c|}{ After 2-stage RHT } \\
\hline \multirow{10}{*}{86} & \multirow{2}{*}{ 3rd tooth } & 543 & 957 & 34.7 & 25.6 \\
\hline & & 531.7 & 948.5 & 36.2 & 27.6 \\
\hline & \multirow{4}{*}{ 2nd tooth } & 572.6 & 998 & 32.4 & 28.8 \\
\hline & & 570.8 & 946.6 & 27.6 & 22.6 \\
\hline & & 562.8 & 967.8 & 34.4 & 23.4 \\
\hline & & 553.4 & 944 & 27.4 & 23.3 \\
\hline & \multirow{4}{*}{$\begin{array}{l}\text { Airfoil lower part, } \\
\text { leading edge, core }\end{array}$} & 499.2 & 929 & 31.2 & 23.4 \\
\hline & & 566.6 & 931 & 35.5 & 24.6 \\
\hline & & 514.6 & 943.8 & 33.6 & 22.7 \\
\hline & & 514.6 & 935 & 32 & 22.8 \\
\hline \multicolumn{2}{|c|}{ Requirements to TU 14-1-2662-79 } & 500 & 850 & 20 & 22 \\
\hline
\end{tabular}

performed on MI-9/1k samples (test part diameter of $5 \mathrm{~mm}$, test section length of $25 \mathrm{~mm}$ ) to PWI specification, cut out of the metal of root upper tooth and from airfoil lower part in its most massive region, adjacent to leading edge.

After RHT, strength level (756.5-780.0 MPa) greatly exceeded the level of $650 \mathrm{MPa}$ specified by the TU for the alloy. It was, however, somewhat lower than the results of testing metal after operation (867 MPa). Ductility of blade metal after RHT was higher than that of blade metal after operation, and was equal to $\delta=36.8-38.9$ and $\psi=30.1-40.8 \%$, respectively, compared to 22.2 and $26.9 \%$. Also noticeable is a certain increase of ultimate strength and ductility exactly after two-stage heat treatment process. RHT ensured increase of fracture energy and elongation, and yield limit and ultimate strength of base alloy EI 893 somewhat decreased, compared to the alloy after long-term operation of the items. Practically 1.5 times higher values of elongation and reduction were obtained, compared to the data after operation at almost the same strength level. This is indicative of much greater fracture energy of material at tensile testing (area under deformation diagram curve) (Figure 8).

Value of EI $893 \mathrm{VD}$ alloy elongation, equal to $20 \%$ and less at $750{ }^{\circ} \mathrm{C}$, is critical in terms of irreversible lowering of blade metal fracture toughness. Elongation and degree of reduction in cross-sectional area of the stretched sample, preceding fracture, is determined by many factors, in particular, grain size and volume fraction of particles of the main strengthening phase and secondary phase particles, precipitating both in the bulk and on boundaries of grains (see Table 3). True deformation at fracture of high-temperature nickel alloys decreases markedly, with increase of volume content of hard carbide and boride particles, which is exactly what was observed in operation.

Analysis of sample fractures after tensile testing provides the required additional information on EI 893 alloy metal structure, uniformity of phase component distribution, features of their plastic deformation 
Table 5. Mechanical properties of metal of GTK 10-4 working blades at $750{ }^{\circ} \mathrm{C}$ after operation and $\mathrm{RHT}$ in vacuum

\begin{tabular}{|c|c|c|c|c|c|}
\hline $\begin{array}{c}\text { Blade } \\
\text { number }\end{array}$ & $\begin{array}{l}\text { Analysis } \\
\text { location }\end{array}$ & $\begin{array}{l}\sigma_{0.2}, \\
\mathrm{MPa}\end{array}$ & $\begin{array}{c}\sigma_{\mathrm{t}} \\
\mathrm{MPa}\end{array}$ & $\begin{array}{l}\delta \\
\%\end{array}$ & $\begin{array}{l}\psi, \\
\%\end{array}$ \\
\hline \multicolumn{6}{|c|}{ After $57,000 \mathrm{~h}$ of operation } \\
\hline 86 & \multirow{2}{*}{ 1st tooth } & 515.8 & 870.3 & 23.6 & 27.7 \\
\hline 16 & & 524.5 & 864.2 & 20.8 & 26 \\
\hline \multicolumn{6}{|c|}{ After 3-stage RHT } \\
\hline \multirow{2}{*}{151} & \multirow{6}{*}{ 1st tooth } & 542 & 794.3 & 36.8 & 45.2 \\
\hline & & 532.3 & 786 & 39.2 & 48.4 \\
\hline \multirow{2}{*}{123} & & 460.2 & 746.3 & 37.8 & 39.4 \\
\hline & & 462 & 736.8 & 35.2 & 42.2 \\
\hline \multirow{2}{*}{122} & & 439.6 & 739.3 & 36.4 & 39.2 \\
\hline & & 437.8 & 736.3 & 35.4 & 36.2 \\
\hline \multicolumn{6}{|c|}{ After 2-stage RHT } \\
\hline 16 & \multirow{5}{*}{$\begin{array}{l}\text { Airfoil lower part, } \\
\text { leading edge, } \\
\text { core }\end{array}$} & & & & \\
\hline 17 & & 445 & 781 & 41.2 & 29.2 \\
\hline & & 469.6 & 784.3 & 37 & 29.4 \\
\hline 19 & & 449.6 & 784.3 & 39.5 & 29.4 \\
\hline 20 & & 443 & 771.3 & 37.7 & 32.5 \\
\hline \multicolumn{2}{|c|}{$\begin{array}{c}\text { Requirements } \\
\text { to TU 14-1-2662-79 }\end{array}$} & N/D & 650 & 11 & 15 \\
\hline
\end{tabular}

(transcrystalline or intergranular fracture), defects, microporosity, and on obvious stress raisers, leading to premature fracture of material. In high-temperature operation of blades, the developing ageing processes lead to segregation of secondary phases on grain boundaries, resulting in ductility lowering. The shape of inclusion particles, according to the data of $[8,10]$, influences the ductility, namely, elongated inclusions cause greater embitterment than do the equiaxed ones. At application of external load, inner cavities can form in the alloy matrix, when local stress exceeds the strength of adhesion of the inclusion to the matrix solution, and tearing occurs over the interface, or in the case of fracture of second phase particles proper.

The higher the intensity of strain hardening, the smaller the strain, required for stress increase to the level leading to particles tearing from the matrix. At deformating of multiphase structure with relatively soft matrix, the main deformation occurs in the solid solution. At a certain concentration of hard (brittle) excess carbide phases, the maximum strength is achieved, when these phases are the most refined (uncoagulated), and particles precipitate in the matrix with minimum intervals (interparticle distances) [11, 12]. Thus, operating time and initial chemical composition of metal of a specific blade will determine its real residual fatigue life.

Application of multistage RHT allows reaching uniform distribution of all interstitial impurities in the matrix. Homogenizing temperature above $1160{ }^{\circ} \mathrm{C}$ is inadmissible, as the grain will start growing. In such a case, we will not achieve the required uniformity of strengthening phase precipitation in the alloy matrix and material fracture toughness respectively.

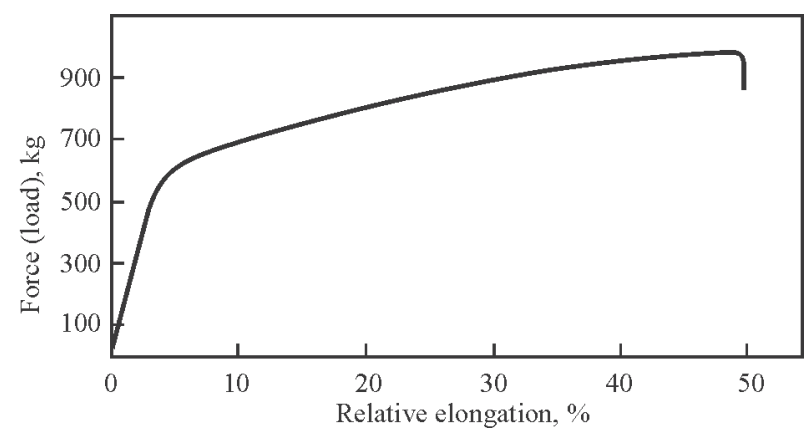

Figure 8. Typical diagram of strain hardening of cylindrical samples of EI $893 \mathrm{VD}$ alloy after undetermined operating period and RHT at uniaxial tension at $20^{\circ} \mathrm{C}$ with $\varepsilon=1.6 \cdot 10^{-3} 1 / \mathrm{s}, \sigma_{\mathrm{t}}=$ $=963.4 \mathrm{MPa}, \sigma_{0.2}=514.6 \mathrm{MPa}$ and $\delta=45 \%$

Figure 9 gives the characteristic microstructures of fracture surface of cylindrical samples of RH-treated EI 893 alloy after testing for uniaxial tension. Analysis of fracture pattern of EI 893 alloy samples from GTK 10-4 working blades after operation and RHT showed that fracture, on the whole, is similar, irrespective of material state: it is ductile fracture, occurring over a plane normal to sample axis [13], without formation of local necking on working surface. On microscopic scale, fracture along the normal is fracture from inner necking or from massive shear along alternating planes inside each separate grain, reaching the intergranular boundary (Figure 10).

In fracture of samples, made from blade material after operation, predominantly intragranular (transcrystalline) fracture is visible (see Figure 9, $a, c$ ). Intercrystalline fracture sites are observed simultaneously, which are due to predominant precipitation of carbide phase particles, as a result of natural ageing of EI 893 alloy at long-term operation. Intergranular surface shows pits from carbide particles, precipitating on the boundaries (Figure 9, e). Hard particles are stress raisers and generate sliding dislocation displacement to adjacent grains. This way, running of uniform plastic deformation in polycrystalline sample volume is ensured at the initial loading stage.

RHT technology, promoting homogenizing of blade metal structure and refining of strengthening phase particles, makes plastic deformation more uniform through the entire polycrystal volume, ensuring plastic flow in the regions, directly adjacent to grain boundaries. Fracture appearance and repeated form of stretching diagrams, point to a low intensity of strain hardening (see Figure 8). It follows that considerable deformation should be applied to achieve such a stress level, which will lead to particle tearing from the matrix, and cause formation of discontinuities in polycrystal volume. After RHT ductile fracture mode prevailed in all the samples (see Figure 9). Ductile fracture pits were observed on fractograms of samples, cut out of set blades and subjected to RHT. So, a 

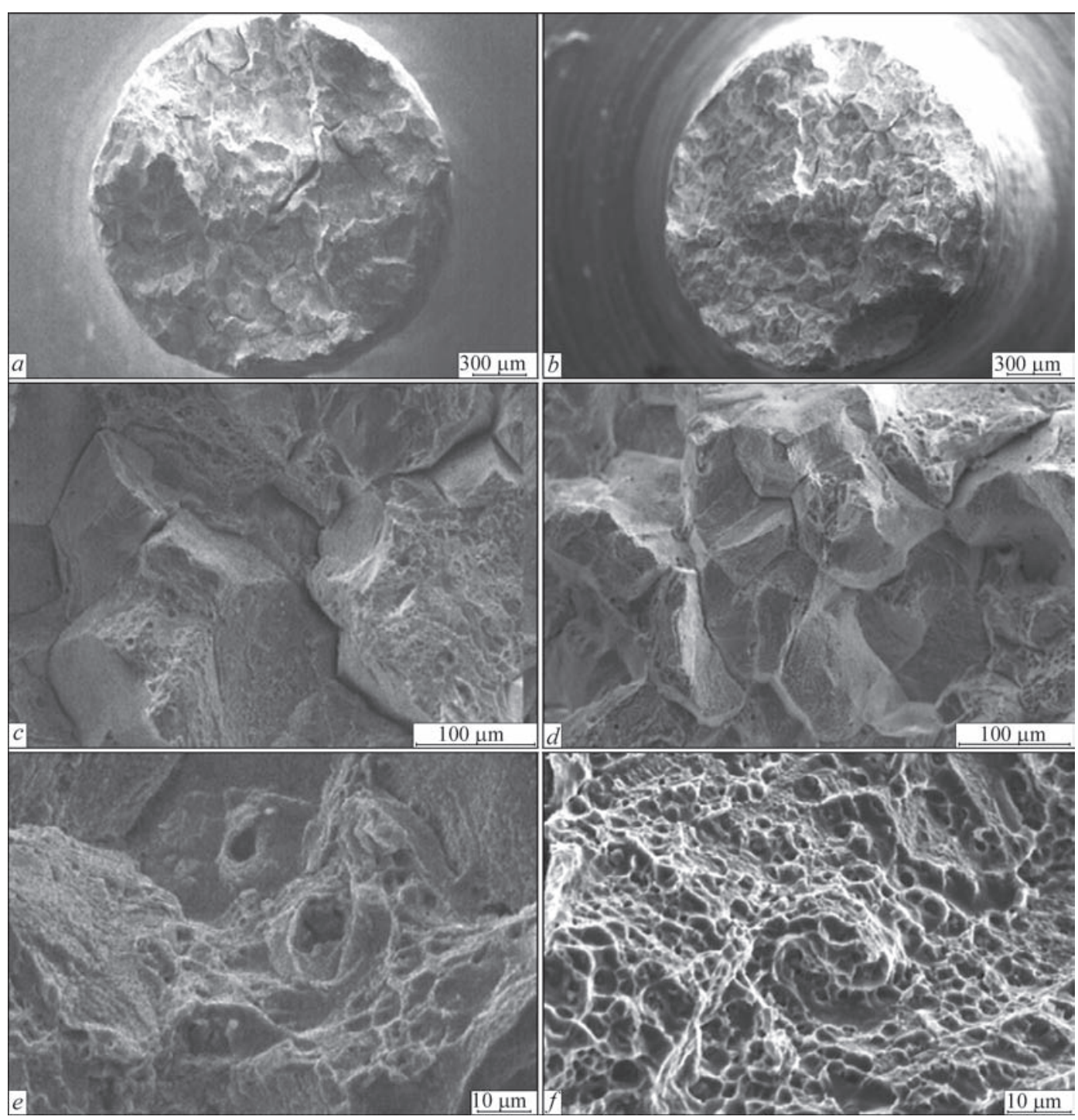

Figure 9. Fracture mode of samples prepared from blade EI 893 alloy after undetermined operating period ( $a, c, e)$ and RHT ( $b, d, f)$

sample, cut out of a tooth of GTK 10-4 RL root after RHT, had relative elongation of $33.2 \%$. It was characterized by practically complete ductile (pit) fracture with minor elements of intergranular fracture. Shear deformation prevailed in the grain bulk (see Figure $9, d, f)$.

As the intensity of strain hardening decreases in nickel alloys with FCC lattice with temperature rise, reduction in area should increase, which we observed in experiments (see Tables 4 and 5). Increase of localized ductility was compensated by a certain lowering of uniform elongation of samples, that is indicative of operational reliability.

Alloys, strengthened, predominantly, through solid solution alloying, should have higher fatigue fracture resistance, owing to increased slip resistance and strain hardening resistance, respectively. Ability to accommodate strain hardening increases fatigue life, owing to increased slip dispersion. It is anticipated that the technology of anticorrosion protection of working blades, using surface plastic deformation of coatings on blades, will provide increased fatigue fracture resistance. Thus, EI 893 alloy, at preservation of chemical composition, is little prone to fatigue fracture compared to high-temperature alloys, as large fracture energy is required for sample fracture.

In the case of wrought alloys, strengthening $\gamma^{\prime}$ phase is structurally unstable. Particularly, at increased temperature of $700-750{ }^{\circ} \mathrm{C}$ (blade airfoil) and availability of temperature gradient along blade airfoil, non-uniformity of its distribution and non-uniformity of particle size are observed. This may cause stress concentration in the blade in operation and lowering of metal endurance. In this respect, there is the risk of formation of «pure» zones near the crystallite boundaries, associated with carbide phase precipitation on the boundaries. Deformation bands form in such precipitation-free near-boundary regions, which may lead to microcrack initiation and fatigue fracture.

Inclusions and microvoids have a strong influence on metal fatigue resistance. Coarse $\mathrm{MeC}$ or $\mathrm{Me}_{6} \mathrm{C}$ carbide particles, forming on crystallite boundaries after 

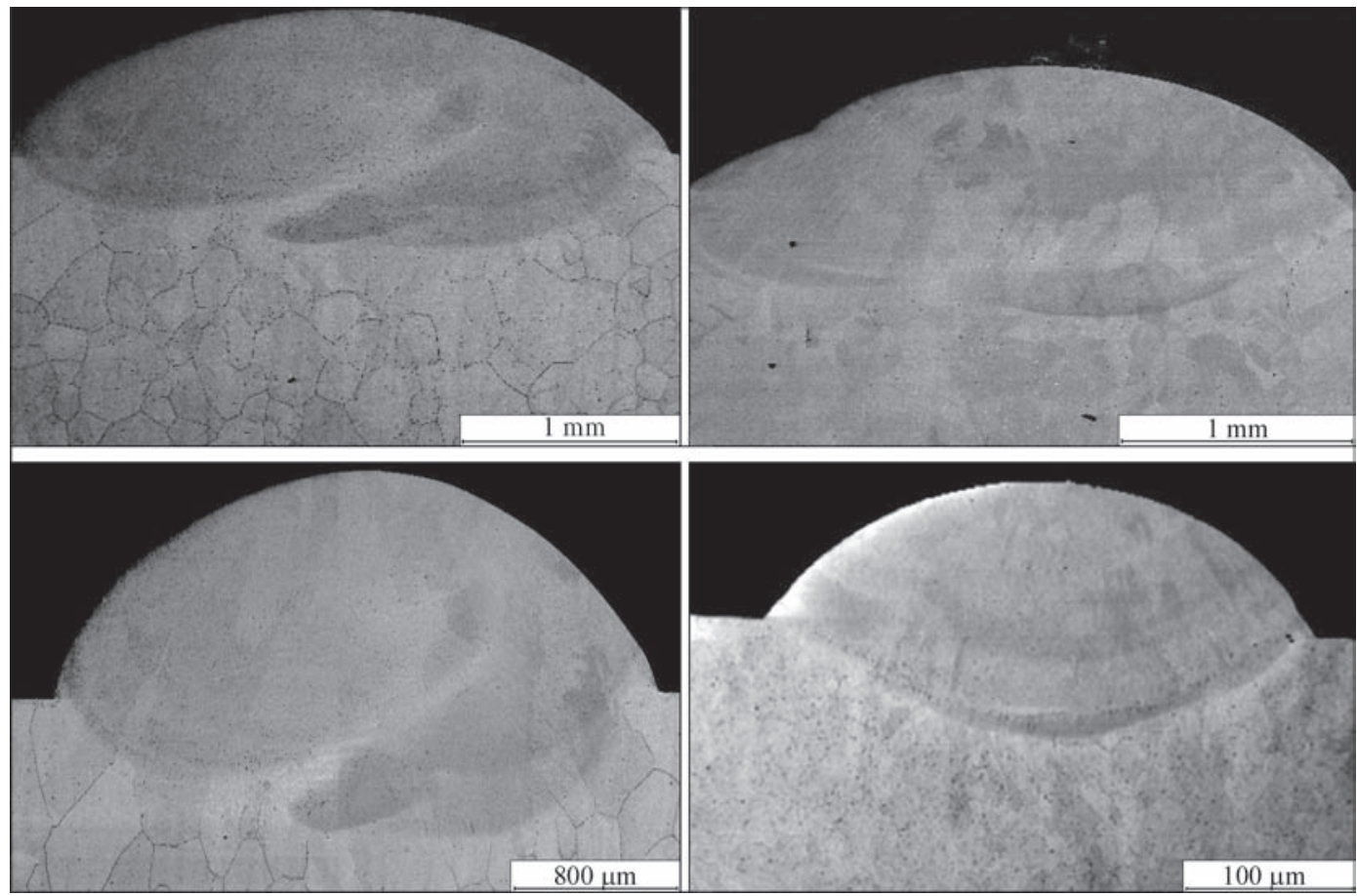

Figure 10. Microstructure of welds deposited on upper tips of airfoil of different working blades from EI 893 alloy with IN-625 welding wire after two-stage RHT

more than $50,000 \mathrm{~h}$ of operation, lower the fatigue life, while non-metallic inclusions or faceted pores can be the site of fatigue fracture initiation, in view of the difference of their and matrix solution moduli of elasticity. Fatigue at operating temperature is largely similar to fracture at creep, which makes a significant contribution into total deformation on grain boundaries. Pores on grain boundaries and wedge cracks become fatigue fracture sites. At increased temperature, oriented slipping along certain crystallographic planes is inhibited and replaced by intergranular fracture.

Evolution of initial alloy microstructure proceeds during long-term high-temperature testing. Thermally activated microstructural changes in a certain way influence the time characteristics of long-term strength, particularly at exposure to corroding medium, which the products of fuel combustion are.

Different level of fatigue life - fatigue and creep resistance - can be achieved, depending on the size of $\gamma^{\prime}$-phase particles in EI $893 \mathrm{VD}$ alloy, associated with deviations of matrix composition and heat treatment type. So, at optimizing of the size of strengthening $\gamma^{\prime}$-phase particles by selection of the mode of high-temperature ageing (RHT), creep deformation of polycrystalline material can be reduced, thus increasing its fatigue resistance $[7,10]$. Long-term strength and creep limit are design characteristics of structural strength of GTU working blades.

At blade operation in the turbine, the impact of aggressive gas flow at high temperature can result in depletion of the surface layer of the part, particularly, in the airfoil upper part, in titanium, aluminium and chromium, and oxide particles of aluminium and titanium can form in it. Data of testing working blades for structural endurance, obtained by authors of [14], showed that lowering of alloying element content in surface layer of EI 893 alloy blades of 30 to $100 \mu \mathrm{m}$ depth does not have any significant influence on endurance limit value. Fatigue resistance level with $50 \%$ fracture probability in new parts, and in blades with dealloyed zone depth of $30 \mu \mathrm{m}$, corresponding to $25,000-32,000 \mathrm{~h}$ of operation in the turbine, is approximately the same and equal to $\sigma_{-1}=150 \mathrm{MPa}$. Sensitivity to presence of dealloyed zone is manifested only in the region of stresses, exceeding endurance limit $\left(\sigma_{\max }=200 \mathrm{MPa}\right)$, when number of cycles to fracture was equal to $N_{\mathrm{f}}=1.7 \cdot 10^{6}$, compared to base experimental value of $3.2 \cdot 10^{6}$ cycles [14]. Thus, if lowering of structural endurance limit of blades after prolonged operation is observed, the cause for this phenomenon should be attributed to presence of surface defects (nicks, dents, undercuts), causing stress concentration in blade airfoil critical sections. The authors of [15] also showed that defects of mechanical origin and variation of edges rounding-off radius have a significant role in fatigue crack initiation in parts operation in the turbine.

It follows from the above said that recovery of alloy structure, preservation of part geometry and sound preparation of blade surface ensure operational reliability of the item. As was shown, structure optimization is achieved at two-stage RHT mode. High-tem- 
perature ageing at $1040{ }^{\circ} \mathrm{C}$ is designed for structure stabilization, namely, dissolution of present irregular coagulated $\gamma^{\prime}$-phase in grain center and on the boundaries; dissolution of unstable chromium carbides (and clusters) of $\mathrm{Me}_{23} \mathrm{C}_{6}$ type, formed in long-term operation, and partial dissolution and refinement of quite stable $\mathrm{MeC}$ and $\mathrm{Me}_{6} \mathrm{C}$ carbides (up to $0.5-1.0 \mu \mathrm{m}$ ) on grain boundaries and their uniform distribution. Low-temperature ageing at $820{ }^{\circ} \mathrm{C}$ leads to regular precipitation of the main strain-hardening $\gamma^{\prime}$-phase of $0.07-0.12 \mu \mathrm{m}$ size with $9-11 \%$ bulk density.

Building-up of upper tip of GTK 10-4 working blades was performed by argon-arc surfacing with IN-625 wire of the following composition, wt.\%: $\mathrm{Ni}-21.5 \mathrm{Cr}-9 \mathrm{Mo}-3.6 \mathrm{Nb}-1 \mathrm{Co}-0.4 \mathrm{Al}-0.4 \mathrm{Ti}-0.5 \mathrm{Si}-$ $0.5 \mathrm{Mn}-0.1 \mathrm{C}$. Surfacing with application of this filler material was performed on samples, cut out of seven working blades after different operating periods. Samples were built-up in as-delivered condition without pre-homogenizing, which was followed by twostage heat treatment.

Analysis of sample structure after all the stages of RHT showed that repaired sections had no defects of any kind, namely solidification cracks, pores, lacks-of-penetration, etc. (see Figure 10). This was the result of correct selection of low-alloyed filler material for welding solid solution strengthening nickel alloy. Deposit metal was dense and was characterized by cellular-dendritic structure with discrete dispersed precipitations of strengthening carbide phases on individual crystallite boundaries.

Weld structure clearly shows the boundary of transition from fusion line to base EI 893 metal. Difference in composition of IN-625 welding wire and blade alloy promoted redistribution on the fusion line of base and filler components ( $\mathrm{Nb}, \mathrm{W}, \mathrm{Mo}$, Ti, etc.) in solidified metal.

HAZ, the depth of which was equal to about $500 \mu \mathrm{m}$, did not contain any cracks, boundary eutectics or pores. Microhardness of base alloy was equal to $H_{\mu}=2350-2700 \mathrm{MPa}$, as a result of precipitation of the main and redistribution of secondary strengthening phases. As weld metal is matrix $\gamma$-solid solution, weakly strengthened by dispersed carbide phases, its microhardness was equal to approximately $2515 \mathrm{MPa}$, and in the HAZ microhardness increased to $2800 \mathrm{MPa}$. Therefore, microhardness of different zones of all the deposited welds was close in value and ensured the serviceability of reconditioned blade sections.

Proceeding from the results of present and earlier research of numerous GTK 10-4 working blades made from EI 893 alloy, we can say that these items are little prone to fatigue fracture at standard oper- ating conditions of all the turbine components. So, fracture of blades of GTK 10-4 set, which has operated for 78,000 h (Berdichev, Ukraine) occurred for a number of reasons, namely unsatisfactory preparation of part edges, corrosion-fatigue impact of fuel combustion products, irreversible overageing of base alloy, and impact of foreign bodies [16]. As no intermediate RHT was performed for this set, blade metal was characterized by irreversible overageing, which in the presence of increased stress raisers and mechanical impact led to rapid destruction of items. Microstructure of EI 893 metal of blades, being in an overaged state and not having sufficient resistance to crack propagation (as a result of lowering of fracture energy), was the material science cause of accelerated fatigue fracture (endurance lowering) of blades in thermophysical and gas-dynamic studies of modified combustion chamber.

Therefore, RHT performance is required after first 45,000-55,000 h of operation. Above 65,000$70,000 \mathrm{~h}$ irreversible structural changes occur in EI 893 alloy at operational ageing, leading to lowering of ductility and fracture toughness. Recovery of initial structure and mechanical characteristics of metal of working blades with different operating time, after RHT performance can guarantee them an additional operating life of 20,000-24,000 h.

\section{Conclusions}

A procedure was developed for determination of repairability of GTK 10-4 HPT and LPT set working blades after different operating periods, including visual inspection, geometry control, penetrant inspection, metallographic macro- and microanalyses, chemical and phase analysis of base alloy EI 893. It is established that an essential change of structural-phase state of base material takes place during prolonged operation (operational ageing at $630-670{ }^{\circ} \mathrm{C}$ ) of working blades, made of EI 893 alloy, determining the change of its mechanical properties, compared to metal in the initial state, namely increase of ultimate strength, yield point, hardness and lowering of ductility properties.

Comprehensive metallographic studies were conducted on optimization of the modes of RHT of GTK 10-4 HPT and LPT working blades. It is established that two-stage RHT ensures structural regeneration of EI 893 base alloy after operation (45,000-55,000 h). Data of mechanical testing at room and working temperature and data on hardness and microhardness confirmed recovery of base properties and their full compliance with EI 893 VD alloy TU: after RHT performance blade metal hardness and ultimate strength 
somewhat decrease and ductility rises (to $\delta \approx 33.2-$ $35.6 \%$ ) that exceeds the properties of initial EI 893 VD alloy before mounting the blades in the turbine.

Selected two-stage RHT mode did not have any adverse impact on formation of dense sound welds at reconditioning the working blade airfoil tip, using IN625 filler material.

Reversibility of structural changes of working blade metal at correspondence of chemical composition to nominal composition of EI 893 alloy guarantees an additional operating life of 20,000-24,000 h to them after RHT performance, owing to correspondence of structure and mechanical properties of reconditioned blade metal to its initial state.

1. Verin, A.D., Sims, C.T., Hagel, W.C. (1976) Microstructure and properties of heat-resistant alloys. In: Heat-resistant alloys. 207-241. Moscow: Metallurgiya.

2. Getsov, L.B. (1996) Materials and strength of gas turbine parts. Moscow: Nadra.

3. Majner, R.V. (1995) Fatigue. Superalloys II. Heat-resistant materials for aerospace and industrial power plants, Vol. 1, 336-372. Moscow: Metallurgiya.

4. Nemajzer, Yu.A., Gursky, G.L., Dobina, N.I. et al. (1982) Influence of grain size on structural fatigue strength of blades from KhN65VMTYu (EI 893) alloy. Energomashinostroenie, 5, 18-21.

5. Pigrova, G.D., Kabanov, B.S., Sedov, V.M. (2002) Method of physico-chemical phase analysis for evaluation of structural state of heat-resistant materials in life prediction. Trudy NPO TsKTI, Issue 289, 39-47.
6. Shajdak, B.P., Ivanov, S.A., Ivanov, A.V. et al. (2002) Prolongation of service life of blades of drive gas turbine units. Service life and reliability of materials and welded joints of power plants. Ibid., 191-204.

7. Berdnik, O.B., Tsaryova, I.N., Razov, E.N. (2011) Development of technology for prolongation of life of KhN65VMTYu alloy turbine blades. Vestnik SamarGAKU, 27(3), 240-246.

8. Pigrova, G.D. (2006) Diagnostics of structural changes in metal of GTU parts during operation by the method of phase physico-chemical analysis. Trudy NPO TsKTI, Issue 295, 55-64.

9. (2005) Development of procedure for prolongation of the life of GTK 10-4 GPU (HPT) $1^{\text {st }}$ stage blades and specifying the life of repaired BKF-05 set: Report of RC Pratt \& Whitney Paton. Kiev.

10. Rybnikov, A.I., Kryukov, I.I. (2006) Carbide transformations in intergranular interlayers of heat-resistant nickel-base alloys during ageing and long-term operation. Trudy NPO TsKTI, Issue $295,154-163$.

11. Rybnikov, A.I., Shajdak, B.P., Ivanov, S.A. (2006) Influence of structural factor on structural fatigue strength of blades of stationary GTU. Ibid., 79-90.

12. Getsov, L.B. (2010) Materials and strength of gas turbine parts, Vol. 1. Rybinsk: Gasoturb. Technologii.

13. Fridman, Ya.B. (1974) Mechanical properties of metals, Vol. 2. Moscow: Mashinostroenie.

14. Sorokin, V.G., Guzanov, B.N., Kositsyn, S.V. et al. (1980) Study of EI 893 alloy blades after long-term operation in gas turbine unit. Energomashinostroenie, 3, 25, 26, 29.

15. (2000) Instructions on investigation of causes of blading fracture of gas turbine units in gas-pumping units. Moscow: Gazprom, VNIIGAZ.

16. (2005) Analysis of causes of spontaneous fracture of GTK 10-4 unit HPT $1^{\text {st }}$ stage blades, CS Berdichev (after 78,000 h of operation): Report of RC Pratt \& Whitney Paton. Kiev.

Received 30.12.2015 